\title{
Introduction of European Priority Review Vouchers to Encourage Development of New Medicines for Neglected Diseases
}

\section{David B Ridley}

Duke University, Durham, NC, USA, david.ridley <at> duke.edu

\section{Alfonso Calles Sánchez}

Duke University, Durham, NC, USA and Spanish Patent Office, Madrid, Spain

Abstract: Every year 1 billion people worldwide are affected by traditionally neglected diseases, such as malaria, tuberculosis, leishmaniasis, and lymphatic filariasis, which impose tremendous public health burdens. Governments, foundations, and drug manufacturers have, however, started to support development of new treatments. European Union Member States have been leaders in implementing so-called push mechanisms (payment for drug development) and pull funding (reward for output), such as the advance market commitment, which creates a market for vaccines by guaranteeing prices. We propose an additional step that could be taken to encourage development of medicines for neglected diseases. A priority review voucher scheme, as is already in place in the USA, would reward a manufacturer that developed a new medicine for neglected diseases with a voucher that could be redeemed for priority review of a future medicine, probably a potential blockbuster drug. Unlike the US system a European voucher would also accelerate pricing and reimbursement decisions. This scheme would be likely to provide substantial benefits to voucher holders, society, and public health organisations.

Notice: this is the author's version of a work that was accepted for publication in The Lancet. Changes resulting from the publishing process may not be reflected in this document. Changes may have been made to this work since it was submitted for publication. A definitive version appears in The Lancet, Vol. 376, No. 9744, September 2010. 


\section{Introduction}

Diseases such as malaria, tuberculosis, leishmaniasis, and lymphatic filariasis impose substantial health burdens but are widely neglected because there is little incentive in the private market to develop new treatments. ${ }^{1}$ Most of the 1 billion people affected by neglected diseases live in low-income countries. ${ }^{2}$ Improvement of health conditions in developing countries is among the UN Millennium Development Goals.

Governments and foundations have recognised the dearth of private-sector incentives and have provided so-called push funds for research and development (funding for drug development) ${ }^{3}$ and pull mechanisms (rewards for output) to reward successful development. ${ }^{4}$ One important pull mechanism is the advance market commitment, which creates a market for vaccines by guaranteeing prices. ${ }^{5}$ Through such efforts, governments of the European Union (EU) Member States have been leaders in encouraging development of treatments for neglected diseases. Here we propose a new incentive mechanism for the EU.

\section{Priority review vouchers}

The priority review voucher scheme is a market-driven incentive that rewards developers of new medicines for a neglected disease. The scheme is already available in the USA, with decisions being made by the Food and Drug Administration (FDA). It was proposed by Duke University faculty members (DBR, Henry Grabowski, and Jeffrey Moe) in 2006, ${ }^{6}$ became law in 2007, and the first voucher was awarded to Novartis in 2009 after FDA approval of Coartem (artemether and lumefantrine) for the treatment of malaria.

In exchange for registration of a new drug for a neglected disease, the manufacturer receives a voucher for priority regulatory review of another medicine. The voucher can be transferred to another company. The drug to which the voucher is applied is likely to be a potential blockbuster treatment, such as an LDL-cholesterol-lowering drug. The benefit of earlier approval of such a drug could be worth several hundred million dollars to the voucher holder.

We propose the introduction of a priority review voucher scheme for the EU, to be awarded by the European Medicines Agency (EMA) or European Commission. For each new neglecteddisease therapy approved, the developer would be awarded a voucher for priority marketing authorisation and accelerated pricing and reimbursement procedures for a medicine of the developer's choice. The pricing and reimbursement feature differs from the US version of the programme, which only accelerates FDA scientific review; the US Government plays a small part 
in negotiating prices with manufacturers, whereas pricing and reimbursement negotiations in Europe are important and time-consuming features of government involvement. ${ }^{7}$

We suggest that each awarded voucher could be transferred between companies and organisations multiple times. Thus, the original voucher recipient would not need to develop both the neglected-disease medicine and the medicine for which the voucher is used. For instance, the developer of the neglected-disease medicine might be a small biotech company, a foundation, or an academic institution. These nonprofit developers could use the proceeds from transfer of the voucher to fund additional neglected-disease research or support access to existing medicines. The voucher would be returned to the regulator if the final bearer did not fulfill accelerated assessment requirements at the EMA. The EMA could charge a supplemental fee (e.g., €1-2 million) to cover additional administrative costs of accelerated review. We estimate that the average value of the EU priority review vouchers would be similar to that of the US vouchers. ${ }^{6,8,9}$ These incentives should at least motivate firms to ensure that medicines for neglected diseases reach late-stage clinical trials.

\section{Marketing authorisation}

Two types of marketing authorisation are given in Europe: that granted by medicines agencies at the national level, and EU-wide authorisation granted by the European Commission after receipt of a positive scientific opinion from the EMA and centralised scientific assessment of an application from the manufacturer. ${ }^{10}$ The centralised procedure is compulsory for specific medicinal products listed in the Annex to the Regulation (EC) 726/2004, including those developed under certain biotechnology processes, new active substances for treatment of AIDS, medicines developed for cancer, diabetes, neurodegenerative disorders, and viral diseases, and medicines designated orphan status. ${ }^{10}$ For other products the centralised procedure is optional for some and unavailable for others. ${ }^{10}$

Access to the centralised approval process and accelerated assessment for the voucher bearer's drug of choice would be granted, even if the medicine would not otherwise be eligible for centralised or accelerated assessment under Article 10(9) of Regulation 726/2004. Accelerated assessment is currently rare and generally applies only to innovative medicines of major public health interest. In these cases, the EMA's Committee for Medicinal Products for Human Use renders a scientific opinion within 150 days. In addition, up to 30 days of so-called clock stops are allowed during the process to enable the submission of additional information by the applicant if it is requested by the scientific committee. By contrast, non-accelerated assessments must be completed within 210 days, but there is no limit on total clock-stop time. The average clock-stop time for 1996-2007 was 151 days (table 1). 
The current regulatory time lines indicate that accelerated assessment at EMA should save the manufacturer about 2 months. In practice, however, the reduction might be between 1 month and 7 months (table 1). ${ }^{11,12}$ From 1996 to 2007 the average active time saved by accelerated medicines was 67 days excluding clock-stop time, and 202 days including clock-stop time. Accelerated products seem consistently to require less clock-stop time, which helps to maintain accelerated status.

If the central scientific assessment is positive, further time is required for certain administrative procedures to be completed at the EMA and the European Commission before marketing authorisation can be granted. This part of the process does not have a fast-track procedure, but for the medicines approved from 2006 to 2008, administrative time was consistently less than 70 days. $^{12}$

\section{Pricing and reimbursement}

After a drug receives marketing authorisation, manufacturers enter the pricing and reimbursement process, which takes place on a country-by-country basis. In EU Member States individual governments are expected to determine pricing and reimbursement within the framework of the Transparency Directive (Directive 89/105/EEC), which requires that decisions be taken within 180 days of submission. ${ }^{13}$ This deadline is frequently unmet, according to the European Federation of Pharmaceutical Industries and Associations. ${ }^{7}$ Manufacturers of generic products have also complained about delays, although generic drugs seem to receive priority decisions in many EU Member States (table 2).

In our proposal, the priority review voucher would confer accelerated pricing and reimbursement decisions in EU Member States. The European Commission has expressed confidence in the feasibility of fast-track decisions on pricing and reimbursement. ${ }^{14,15}$ Some EU Member States already give priority to generic medicines or orphan medicines during pricing and reimbursement procedures. Amendment of the Transparency Directive or national legislation would enable the introduction of a fast-track procedure. ${ }^{14}$ In France, medicine sales total roughly $€ 25.5$ billion, or around $19 \%$ of the European market. Orphan medicines receive conditional decisions within 15 days, decisions for generic medicines take an average of 75 days and those for branded medicines take an average of 312 days (table 2). A priority decision of 30 days associated with a review voucher would, therefore, save an average of 282 days for proprietary drugs (table 2). Alternatively, the average time saved if the decision time for generic products were applied to proprietary drugs would be 237 days in France. Across Europe, the weighted average time saved (where the weight represents the share of sales per country) 
would be 176 days under the voucher 30-day system, or 123 days if the review time for generic products were applied to proprietary drugs.

A manufacturer with a priority review voucher could still choose to pursue pricing and reimbursement sequentially in different countries. For example, the manufacturer might seek a fast-track decision in countries where higher prices can be charged before submitting paperwork in countries where prices are lower to mitigate price overspill from parallel trade and reference pricing. ${ }^{16}$

We have calculated differences between standard review and accelerated review times for registration and reimbursement decisions. We use data from registration (table 1) and pricing and reimbursement (table 2 ) to estimate two scenarios (table 3 ).

\section{Effective patent life}

A patent term typically begins long before a medicine is approved. In the USA, the HatchWaxman Act restores time lost at the FDA up to 5 years, and the effective patent term is extended up to 14 years. EU Member States also extend the patent protection time to account for time lost in development and review. The limit of extension in the EU is 5 years, and the combined duration of the patent and supplementary protection rarely exceeds 15 years; ${ }^{17}$ terms might be extended to 5.5 years to reward manufacturers that have tested a patented medicine in children. ${ }^{18}$ Unlike patent-term extensions, priority review vouchers will not delay the generic entry date but will extend the effective patent term.

Given the cap on time restored, medicines that take a long time in clinical testing will still have 5 years of patent life restored and the voucher will not change the date of generic entry. By contrast, drugs with fast clinical testing will have fewer than 5 years of patent life restored. By speeding regulatory review for drugs with fast clinical testing, the voucher would typically bring forward the date of generic entry.

Under our proposed scheme some time saved in accelerated review by the EMA could be added to the effective patent term of the medicine. All time saved from expeditious pricing and reimbursement decisions would be added to the effective patent term.

\section{Value of accelerated assessment}

Manufacturers highly value accelerated assessment but it is rare. For instance, in 2006 manufacturers filed 13 requests for accelerated assessment at EMA but only four were granted 
access to the accelerated system, and two of these four were later reverted to standard procedure. ${ }^{19}$ Manufacturers desire fast decisions because early entry brings forward availability in relation to competitors' drugs, enables earlier sales, and lengthens the effective patentprotected time on the market (figure). ${ }^{8}$ Generic entry is not, however, delayed. A priority review voucher scheme would make the advantages of fast decisions available to more manufacturers.

To estimate the potential value of applying a priority review voucher to a top-selling medicine in the EU, we used sales data for five top-selling drugs launched in the late 1990s: Enbrel (etanercept, Immunex, Seattle, WA, USA), Lipitor (atorvastatin, Pfizer, New York, NY, USA), Plavix (clopidogrel, Sanofi-Aventis, Paris, France), Seretide (fluticasone, GlaxoSmithKline, Greenford, UK), and Zyprexa (olanzapine, Eli Lilly, Indianapolis, IN, USA). Data were provided by IMS Spain in Madrid. We included sales figures from 20 countries: Austria, Belgium, Czech Republic, Denmark, Finland, France, Germany, Greece, Hungary, Ireland, Italy, Netherlands, Norway, Poland, Portugal, Slovakia, Spain, Switzerland, Turkey, and the UK. This list includes three non-EU Member States (Norway, Switzerland, and Turkey) and excludes ten Member States, but contributes a reasonable estimate of sales in the EU. We calculated values in constant US\$ by choosing the euro-dollar exchange rate for March 31, 2009.

We calculated the value of shifting sales forward as follows:

value $=\mathrm{AP}(1-\operatorname{tax}) \mathrm{NPV}\left((1+\mathrm{DR})^{\wedge}(\mathrm{ST}-\mathrm{AT})-1\right) /(1+\mathrm{DR})^{\wedge} \mathrm{WT}$

(AP means approval probability, NPV means net present value, DR means discount rate, ST means standard time, AT means accelerated time, and WT means wait time). We assumed a $68.5 \%$ probability of approval, which was the average value for a sample of 68 drugs submitted to the FDA in the 1990s. ${ }^{20}$ This estimate is conservative because the 2008 EMA annual report suggests a higher probability of success in the EU12 and because manufacturers are likely to be confident in the value and likelihood of approval for medicines submitted under the voucher system. We applied an $11 \%$ discount rate, which was derived from industry research findings and reflects the expected return that investors forego when they invest in pharmaceutical development instead of an equally risky portfolio of financial securities. ${ }^{20}$ We assumed that the wait time between acquiring a voucher and approval would be 1 year, and we assumed taxes of $30 \%$. The value of shifting sales forward was $\$ 20$ million per month.

We calculated the value of extending effective patent life as follows:

value $=A P(1-$ tax $)$ sales $/(1+D R)^{\wedge}$ years 
(AP means approval probability and DR means discount rate). The discount and tax rates and probability of approval remained as above. We assumed that the additional sales would occur 11 years after branded launch and estimated that the additional sales would be $\$ 200$ million per month, according to the aforementioned sales data. The net present value of extended patent life was roughly $\$ 30$ million per month, but in reality the first month would be somewhat more valuable than the 12 th month.

We assumed that the assessment time falls from 210 to 150 days, as per the EMA's current accelerated schedule, and estimated time savings of 2 months for assessment. We estimated that an additional 4 months would be saved during pricing and reimbursement assessment if voucher medicines were reviewed at the current average rate of generic medicines (table 3 ). These 6 months saved would be worth $\$ 120$ million from early sales and US\$180 million for additional sales achieved under extended effective patent life, yielding a total value of $\$ 300$ million.

The values above are averages and the potential value of priority review vouchers will vary widely. For example, if all review times for applications approved in 1996-2007 were used to calculate differences, accelerated review would lower the overall assessment time by around 12 months (table 3). If the average worth of the voucher based on moving sales forward and extending effective patent life was $\$ 50$ million per month ( $\$ 20$ million plus $\$ 30$ million), acceleration of 1 year could be worth a total of $\$ 600$ million ( $\$ 240$ million for early sales plus $\$ 360$ million for patent extension; table 3). Conversely, in the conservative scenario (scenario 2 in table 3) we assume no correlation between accelerated review and clock-stop time (taking 36 days for both accelerated and non-accelerated rather than the non-accelerated average of 133 days) and negligible time saved for pricing and reimbursement. If only applications approved in 2007 were used, acceleration would be only 1.5 months and the total worth would be only $\$ 75$ million (\$30 million for early sales plus $\$ 45$ million for patent extension; table 3 ). In the USA, the priority review voucher has been estimated to be worth several hundred million US dollars per product. ${ }^{6,8}$ Sales in Europe are only about $75 \%$ of those in the USA, but the expectation that the value of vouchers will be similar in both regions is reasonable, owing to the high potential for early pricing and reimbursement in Europe.

Several sources of additional value for manufacturers that spent the voucher are omitted from this analysis. First, manufacturers might value the competitive advantage from launching ahead of or closer to a rival (figure). Second, manufacturers might value efficiency associated with the centralised approval process, which would not be available for some medicines without the voucher. 
Society could benefit from earlier access to the potential blockbuster for which the voucher is used. In a simple economic model of linear demand, the surplus (the amount that consumers are willing to pay minus the amount it costs manufacturers to supply additional units) is split between manufacturers and consumers at a ratio of 2:1. We do not rule out the possibility, however, that governments and private insurers could pay prices that exceed a product's value, but this issue is broader than can be addressed here. Finally, the analysis does not account for the considerable advantage to society of developing new medicines that reduce the burden of neglected diseases.

The value of the voucher is sensitive to various influences, such as the probability of approval and rises in tax and discount rates. Any of these features could lower the worth of moving sales forward. However, a substantial reduction in the approval probability is improbable, given that manufacturers would be likely to apply vouchers to products with probability above the mean.

\section{Alternative voucher scheme models}

We propose that priority review vouchers be applied to branded medicines, but they could be extended to generic products, including follow-on biologics. As another alternative, rather than use the priority review voucher as a pull mechanism, vouchers could be auctioned and the proceeds used to fund push mechanisms. ${ }^{21}$ An advantage of auctioning and push funding is that uncertainty in outcomes and waiting times could be diminished for the drug developer. $A$ disadvantage, however, is that the uncertainty and waiting would be transferred to society. Whether push or pull funding is better is unclear, but both are useful methods to motivate development of new medicines for neglected diseases.

\section{Limitations}

The proposed EU voucher scheme has limitations similar to those in the US system. ${ }^{6,8,22-24}$ First, the value of the voucher might be too generous if it rewards research that would be done anyway, but this feature is seen with other incentives, such as rewarding charitable donations with tax deductions even though some of the donations would have been made anyway. Policy makers could consider, among other things, limiting voucher eligibility to molecules that had not previously been approved in Europe and had not been approved in the USA or Japan for more than 2 years before the filing of the application in Europe.

Second, and conversely, the value of the voucher might be too small. Diseases with substantial public health burdens merit sizeable resources. The priority review voucher should not be a substitute for other incentives. 
Third, although priority review vouchers might motivate development of new therapies, they would not pay for access to the therapies. A developer that earns a voucher could sell the voucher and use the money to broaden access to the therapy. Alternatively, funding from governments or foundations might be needed to ensure access to medicines. The Global Fund to Fight AIDS, Tuberculosis and Malaria, for example, provides billions of dollars in funding worldwide for access to medicines.

Fourth, accelerated review could tie up EMA resources. To compensate for the additional burden in the USA, voucher bearers are required to give 1 year's notice of intent to use a voucher and must pay a user fee.

Fifth, there is a possibility that accelerated assessment would compromise safety. Although accelerated review would not shorten or otherwise weaken clinical testing requirements, regulators would have less time to assess the paperwork than in standard review periods. ${ }^{25-27}$

Finally, authorities might ignore vouchers and still make slow decisions. In the USA, review for priority drugs sometimes takes more than 6 months. Whatever the duration of the process, however, the voucher is still valuable if it shortens review time. For pricing and reimbursement certain authorities, such as the French Government, have shown an ability to greatly increase the speed of decisions. For regulatory review, authorities could charge an additional user fee. The manufacturer, the global health community, and political leaders will all be interested in seeing that authorities respect the voucher.

\section{Conclusion}

European governments have made substantial contributions to research and development of medicines for orphan and neglected diseases. The introduction of a priority review voucher scheme in the EU similar to that in the USA would be a useful additional contribution. Like the US version, a European voucher would accelerate regulatory decisions for new drugs. Unlike the US version, a European voucher would also accelerate pricing and reimbursement decisions. The use of similar systems in the two regions could help to expand incentives for developing new treatments for neglected diseases.

\section{Contributors}

Both authors contributed to the writing, review, and editing of this article. 


\section{Conflicts of interest}

In the past 3 years DBR has received consultancy fees from Genentech in relation to follow-on biologics, expert testimony fees from Sandoz in relation to generic-drug pricing, and an honorarium from PhRMA for participating at a conference. AC-S declares that he has no conflicts of interest.

\section{Acknowledgments}

DBR was involved in the original research for the US voucher, which was funded by the GlaxoWellcome Foundation and Duke University's Center for the Advancement of Social Entrepreneurship. We thank Jeffrey Moe, Damon Seils, Jia Yao, Nina Yoshimura, and the reviewers and editors for helpful comments.

\section{References}

1 Trouiller P, Olliaro P, Torreele E, Orbinski J, Laing R, Ford N. Drug development for neglected diseases: a deficient market and a public-health policy failure. Lancet 2002; 259: 2188-94.

2 Department of Control of Neglected Tropical Diseases. Neglected tropical diseases: hidden successes, emerging opportunities. Geneva: World Health Organization, 2009; http://whqlibdoc.who.int/publications/2009/9789241598705_eng.pdf (accessed June 8, 2010).

3 Moran M, Guzman J, Ropars AL, et al. Neglected disease research and development: how much are we really spending? PLoS Med 2009; 6: e30.

4 Towse A, Kettler H. Advance price or purchase commitments to create markets for treatments for diseases of poverty: lessons from three policies. Bull World Health Organ 2005; 83: 30107.

5 Berndt E, Glennerster R, Kremer M, Lee J, Levine R. Advance market commitments for vaccines against neglected diseases: estimating costs and effectiveness. Health Econ 2007; 16: 491-511.

6 Ridley DB, Grabowski HG, Moe JL. Developing drugs for developing countries. Health Aff (Millwood) 2006; 25: 313-24. 
7 Patients W.A.I.T. Indicator phase 8 Report. European Federation of Pharmaceutical Industries and Associations, 2007; http://www.efpia. eu/Content/Default.asp?PagelD=559\&DocID=4900 (accessed July 14, 2010).

8 Grabowski HG, Ridley DB, Moe JL. Priority review vouchers to encourage innovation for neglected diseases. In: Eggleston K, ed. Prescribing cultures and pharmaceutical policy in the Asia-Pacific. Washington, DC: Brookings Institution Press, 2009.

9 Matheny J, Smith B, Courtney B, Mair M. Drug and vaccine development for infectious diseases: the value of priority review vouchers. Clin Pharmacol Ther 2009; 85: 571-72.

10 Regulation (EC) No 726/2004 of the European Parliament and of the Council of 31 March 2004 laying down Community procedures for the authorisation and supervision of medicinal products for human and veterinary use and establishing a European Medicines Agency. European Commission, 2009; http://ec.europa.eu/health/files/eudralex/vol1/reg_2004_726_cons/reg_2004_726_cons_en.pdf (accessed June 8, 2010).

11 Pinheiro MH. Specific key provisions of EU NML facilitating rapid access to medicines. EMEA NML Implementation. Feb 3, 2006; http://www.adediem.com/docs/03-MH\%20Pinheiro\%20\%20 ADEDIEM\%20030206.ppt (accessed June 8, 2010).

12 Annual report of the European Medicines Agency 2008. European Medicines Agency, July, 2009; http://www.emea. europa.eu/pdfs/general/direct/emeaar/AnnualReport2008.pdf (accessed June 8, 2010).

13 European Commission. EU Directive 89/105/EEC relating to the transparency of measures regulating the pricing of medicinal products for human use and their inclusion in the scope of national health insurance systems. Official Journal of the European Union 1989; L040: 8-11.

14 Paragraph 1434 of the Pharmaceutical Inquiry Final Report. European Commission, July, 2009; http://ec.europa.eu/competition/sectors/pharmaceuticals/inquiry/staff_working_ paper_part1.pdf (accessed June 8, 2010).

15 High Level Pharmaceutical Forum 2005-2008. Final conclusions and recommendations. European Commission, November, 2008;

http://ec.europa.eu/pharmaforum/docs/final_conclusions_en.pdf (accessed June 8, 2010).

16 Danzon P, Wang YR, Wang L. The impact of price regulation on the launch delay of new drugs. Health Econ 2005; 14: 269-92. 
17 Article 13 of Council Regulation (EEC) No 1768/92 of 18 June 1992 concerning the creation of a supplementary protection certificate for medicinal products. European Commission, Jan 26, 2007; http://eur-lex.europa.eu/LexUriServ/LexUriServ.do?uri=CONSLEG: 1992R1768:20070126:EN:PDF (accessed June 8, 2010).

18 Calles Sánchez A. Implementing paediatric extensions to SPCs: marketing authorization in 'all Member States'. Oxford University J Intellect Prop Law Pract 2009; 4: 305-06.

19 European Medicines Agency. EMEA concludes first accelerated assessment for a medicine for human use. European Medicines Agency, April 27, 2007; http://www.emea.europa.eu/pdfs/human/press/pr/18487607en.pdf (accessed June 8, 2010).

20 DiMasi JA, Hansen RW, Grabowski HG. The price of innovation: new estimates of drug development costs. J Health Econ 2003; 22: 151-85.

21 Pharmaceutical R\&D Policy Project. Fast track options as a fundraising mechanism to support R\&D into neglected diseases. London School of Economics, January, 2005; http://www.who.int/intellectualproperty/submissions/Mary.Moran2.pdf (accessed June 8, 2010).

22 Kesselheim A. Drug development for neglected diseases-the trouble with FDA review vouchers. N Engl J Med 2008; 359: 1981-83.

23 Moe J, Grabowski H, Ridley D, Kesselheim A. FDA review vouchers. N Engl J Med 2009; 360: 837-38.

24 Sonderhom J. In defense of priority review vouchers. Bioethics 2009; 23: 413-20.

25 Carpenter D, Zucker E, Avorn J. Drug-review deadlines and safety problems. N Engl J Med 2008; 358: 1354-61.

26 Nardinelli C, Lanthier M, Temple R, Carpenter D. Drug-review deadlines and safety problems. N Engl J Med 2008; 359: 95-98.

27 Grabowski H, Wang Y. Do Faster Food and Drug Administration drug reviews adversely affect patient safety? An analysis of the 1992 Prescription Drug User Fee Act. J Law Econ 2008; 51: 377-406. 


\begin{tabular}{|c|c|c|c|c|c|c|c|}
\hline & \multirow[b]{2}{*}{$\begin{array}{l}\text { Year of } \\
\text { scientific } \\
\text { opinion }\end{array}$} & \multicolumn{3}{|c|}{$\begin{array}{c}\text { Durations of accelerated } \\
\text { review (days) }\end{array}$} & \multicolumn{3}{|c|}{$\begin{array}{l}\text { Average durations for non- } \\
\text { accelerated review per year }\end{array}$} \\
\hline & & $\begin{array}{l}\text { Active } \\
\text { time }\end{array}$ & $\begin{array}{l}\text { Total } \\
\text { clock-stop } \\
\text { time }\end{array}$ & $\begin{array}{l}\text { Total } \\
\text { review } \\
\text { time }\end{array}$ & $\begin{array}{l}\text { Active } \\
\text { time }\end{array}$ & $\begin{array}{l}\text { Total clock- } \\
\text { stop time }\end{array}$ & $\begin{array}{l}\text { Total } \\
\text { review } \\
\text { time }\end{array}$ \\
\hline Norvir (ritonavir, Abbot, USA) & 1996 & 69 & 0 & 69 & & & \\
\hline $\begin{array}{c}\text { Crixivan (indinavir, Merck, } \\
\text { USA) }\end{array}$ & 1996 & 85 & 12 & 97 & & & \\
\hline $\begin{array}{c}\text { Zerit (stavudine, Bristol-Myers } \\
\text { Squibb, USA) }\end{array}$ & 1996 & 150 & 0 & 150 & & & \\
\hline $\begin{array}{c}\text { Combivir (lamivudine, } \\
\text { zidovudine, GlaxoSmithKline, } \\
\text { UK) }\end{array}$ & 1997 & 119 & 0 & 119 & & & \\
\hline $\begin{array}{c}\text { Viramune (nevirapine, } \\
\text { Boehringer Ingelheim, } \\
\text { Germany) }\end{array}$ & 1997 & 125 & 0 & 125 & & & \\
\hline $\begin{array}{c}\text { Kaletra (lopinavir, ritonavir, } \\
\text { Abbot, USA) }\end{array}$ & 2000 & 145 & 0 & 145 & 177 & 174 & 351 \\
\hline $\begin{array}{c}\text { HBVAXPRO (Sanofi Pasteur, } \\
\text { UK) }\end{array}$ & 2001 & 70 & 17 & 87 & & & \\
\hline $\begin{array}{l}\text { Viread (tenofovir, Gilead } \\
\text { Sciences, USA) }\end{array}$ & 2001 & 83 & 63 & 146 & & & \\
\hline $\begin{array}{l}\text { Glivec (imatinib, Norvatis, } \\
\text { Switzerland) }\end{array}$ & 2001 & 119 & 0 & 119 & & & \\
\hline $\begin{array}{c}\text { Fuzeon (enfuvirtide, } \\
\text { Hoffmann-La Roche, USA) }\end{array}$ & 2003 & 121 & 28 & 149 & 191 & 200 & 391 \\
\hline $\begin{array}{l}\text { Soliris (eculizumab, Alexion } \\
\text { Pharmaceuticals, USA) }\end{array}$ & 2007 & 147 & 36 & 183 & & & \\
\hline $\begin{array}{c}\text { Isentress (raltegravir, Merck, } \\
\text { USA) }\end{array}$ & 2007 & 141 & 35 & 176 & & & \\
\hline Average 1996-2005 & & 109 & 12 & 121 & 184 & 155 & 339 \\
\hline Average 2006-2007 & & 144 & 36 & 180 & 173 & 133 & 306 \\
\hline Average 1996-2007 & & 115 & 16 & 131 & 182 & 151 & 333 \\
\hline
\end{tabular}

Averages are calculated with each year receiving equal weight. The two time periods of 19962005 and 2006-07 are used because the European Union formally implemented accelerated assessment in 2006. Sources: EMA Annual Reports 1996-2007, European Union Member States, Pinheiro, ${ }^{11}$ and the 2008 European Public Assessment Report. ${ }^{12}$

Table 1: European accelerated marketing authorisation review times for branded drugs versus average non-accelerated review times in 1996-2007 


\begin{tabular}{|c|c|c|c|c|c|}
\hline & \multicolumn{2}{|c|}{$\begin{array}{l}\text { Pricing and reimbursement } \\
\text { period (days) }\end{array}$} & \multicolumn{2}{|c|}{ Time saved (days) } & \multirow{2}{*}{$\begin{array}{l}\text { Total medicine } \\
\text { sales ( } € \text { millions) }\end{array}$} \\
\hline & $\begin{array}{l}\text { Branded } \\
\text { drug }\end{array}$ & Generic drug & $\begin{array}{l}\text { If assessed in } \\
<\mathbf{3 0} \text { days } \\
\text { (voucher } \\
\text { system) }\end{array}$ & $\begin{array}{l}\text { If assessed as } \\
\text { a generic drug }\end{array}$ & \\
\hline Austria & 370 & 180 & 340 & 190 & 2,736 \\
\hline Belgium & 503 & 180 & 473 & 323 & 3,932 \\
\hline Czech & 289 & 90 & 259 & 199 & 542 \\
\hline Denmark & 81 & 14 & 51 & 67 & 1,860 \\
\hline Finland & 151 & 74 & 121 & 77 & 1,848 \\
\hline France & 312 & 75 & 282 & 237 & 25,501 \\
\hline Germany & 0 & 0 & 0 & 0 & 25,241 \\
\hline Greece & 243 & 120 & 213 & 123 & 5,503 \\
\hline Hungary & 351 & 90 & 321 & 261 & 1,955 \\
\hline Ireland & 83 & 30 & 53 & 53 & 1,902 \\
\hline Italy & 333 & 120 & 303 & 213 & 16,734 \\
\hline The Netherlands & 180 & 60 & 150 & 120 & 4,616 \\
\hline Norway & 132 & 130 & 102 & 2 & 1,360 \\
\hline Poland & 214 & 180 & 184 & 34 & 4,237 \\
\hline Portugal & 137 & 111 & 107 & 26 & 3,490 \\
\hline Slovakia & 426 & 400 & 396 & 26 & 846 \\
\hline Spain & 271 & 90 & 241 & 181 & 13,209 \\
\hline Switzerland & 180 & 180 & 150 & 0 & 2,726 \\
\hline UK & 0 & 0 & 0 & 0 & 14,493 \\
\hline Total & & & & & 132,731 \\
\hline $\begin{array}{l}\text { Weighted average } \\
\text { for all countries } \\
\text { (days) }\end{array}$ & 197 & 74 & 176 & 123 & \\
\hline
\end{tabular}

Table 2. Pricing and reimbursement time in Europe

Sources: W.A.I.T. indicator ${ }^{7}$ and a presentation by the European Generic Medicines Association (Perry G. Slide 35, initial speech. European Generic Medicines Association Annual Assembly, Barcelona, May 4, 2009). 


\begin{tabular}{|c|c|c|c|c|}
\hline & \multirow{2}{*}{\multicolumn{2}{|c|}{ Scenario 1}} & & \\
\hline & & & \multicolumn{2}{|c|}{ Scenario 2} \\
\hline & $\begin{array}{c}\text { Standard } \\
\text { review }\end{array}$ & $\begin{array}{l}\text { Accelerated } \\
\text { review }\end{array}$ & $\begin{array}{c}\text { Standard } \\
\text { review }\end{array}$ & $\begin{array}{c}\text { Accelerated } \\
\text { review }\end{array}$ \\
\hline \multicolumn{5}{|l|}{ Before market entry } \\
\hline $\begin{array}{l}\text { Active time (days) (from Table } \\
\text { 1) }\end{array}$ & 182 & 115 & 173 & 144 \\
\hline $\begin{array}{l}\text { Clock stop time (days) (from } \\
\text { Table 1) }\end{array}$ & 151 & 16 & 36 & 36 \\
\hline Administrative time (days) & 60 & 60 & 60 & 60 \\
\hline $\begin{array}{l}\text { Price and reimbursement } \\
\text { (days) (from Table 2) }\end{array}$ & 197 & 30 & 197 & 180 \\
\hline Total time (days) & 590 & 222 & 466 & 420 \\
\hline \multicolumn{5}{|l|}{ After market entry } \\
\hline $\begin{array}{l}\text { Value from earlier sales } \\
\text { (US\$m) assuming } \\
\text { US\$20m/month }\end{array}$ & NA & 240 & NA & 30 \\
\hline $\begin{array}{l}\text { Value from longer sales } \\
\text { (US\$m) assuming } \\
\text { US\$30m/month }\end{array}$ & NA & 360 & NA & 45 \\
\hline
\end{tabular}

Table 3. Time saved and resulting value

*Takes into account review times for all applications for approval granted in the EU in 19962007 in years that at least one drug received accelerated review $(n=234)$, including clock-stop time and assuming a price and reimbursement schedule of 30 days.

tTakes into account granted approval in the EU in 2006-07 ( $n=58)$ and assumes no saving in clock-stop time.

$\ddagger$ Assumes voucher value of US\$20 million per month.

§Assumes voucher value of US\$30 million per month. 


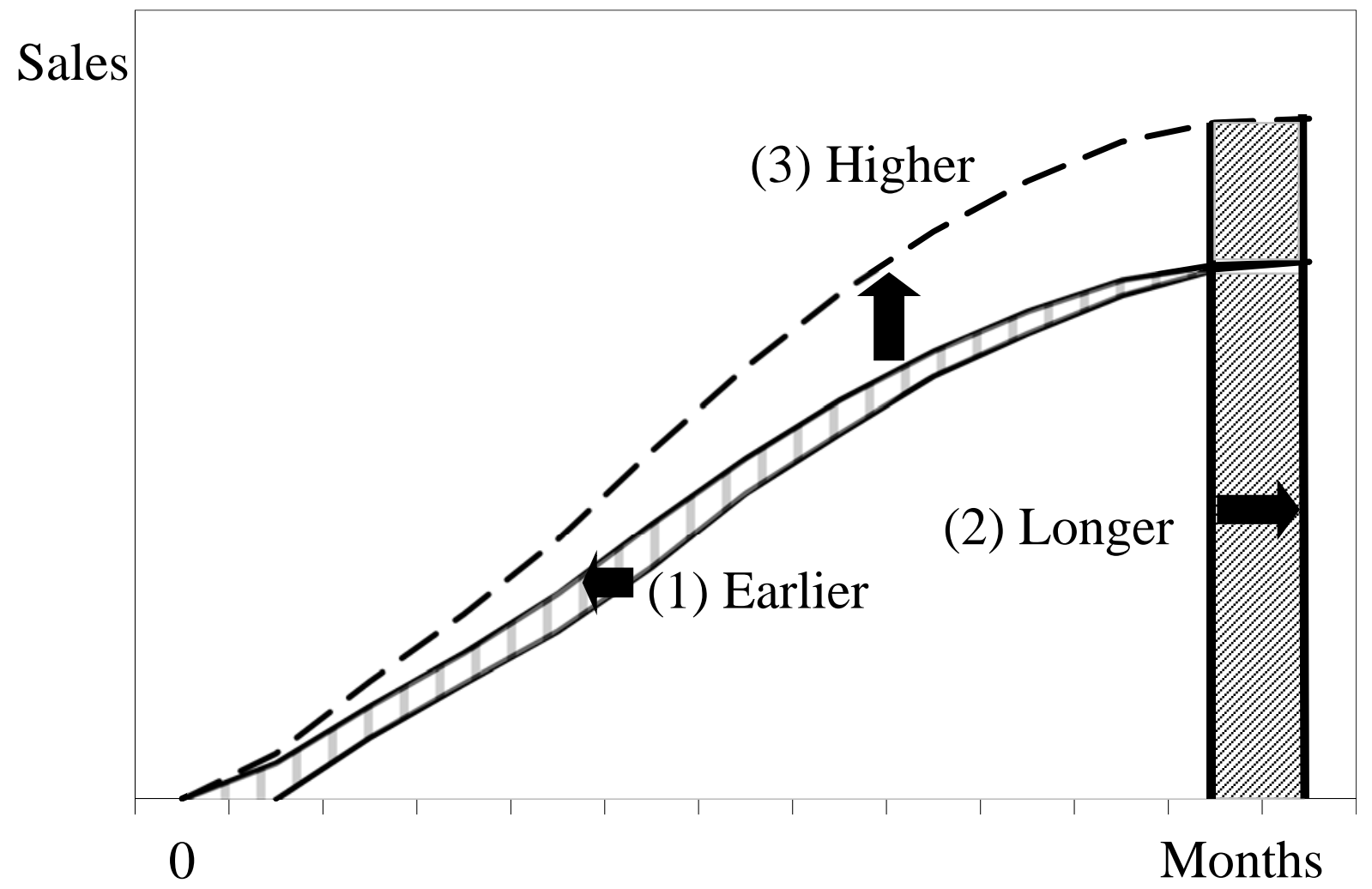

Figure: Priority review voucher value is gained from three main sources

(1) Earlier sales. (2) Increased duration of sales under patent protection owing to earlier introduction to the market. (3) Higher sales from earlier availability compared with rivals' similar drugs. 